\title{
Gestão do conhecimento organizacional: tratamento arquivístico para reuso da informação administrativa
}

\author{
Henrique Machado dos Santos* \\ Gabriela Luisa Krawszuk**
}

Artículo recibido:

29 de julio de 2019

Artículo aceptado:

19 de noviembre de 2019

Artículo de revisión

\section{Resumo}

Este estudo tem por objetivo identificar contribuições da gestão de documentos para o processo de gestão do conhecimento. Tal abordagem limita-se às práticas de gestão do conhecimento desenvolvidas a partir de informações administrativas contidas em documentos produzidos pela própria organização. Assim, discutem-se como tais informações podem ser reutilizadas para desenvolver o conhecimento organizacional. O método utilizado parte do levantamento bibliográfico, limitando-se a seleção de livros relacionados à Administração e Arquivologia, e tem-se a gestão do conhecimento como categoria norteadora. Os dados coletados

* $\quad$ Arquivo Geral, Universidade Federal do Rio Grande, Brasil

henrique.hms.br@gmail.com

** Curso de Administração, Sociedade Educacional Três de Maio, Brasil

gabrielakrausuk@gmail.com

INVESTIGACIÓN BIBLIOTECOLÓGICA, vol. 34, núm. 83, abril/junio, 2020, México, ISSN: 2448-8321 pp. 103-127 
são analisados por meio da triangulação entre Administração, Arquivologia e gestão do conhecimento. A discussão segue a lógica dedutiva, e após essa reflexão, obtém-se um artigo de revisão assistemática, que tece elos interdisciplinares para abordar tal convergência. Dessa forma, a organização pode extrair informações confiáveis por meio de seus documentos, de modo a contribuir para o processo de tomada de decisão, além de fomentar a inovação e desenvolver vantagem competitiva. Pondera-se que o reuso da informação contida nos arquivos permite que os colaboradores racionalizem as atividades em prol da eficiência administrativa. Consequentemente, a sinergia produzida por essas atividades agrega valor organizacional.

Palavras-chave: Administração; Arquivologia; Gestão de documentos; Capital intelectual

Gestión del conocimiento organizacional: tratamiento archivístico para la reutilización de información administrativa

Henrique Machado dos Santos y Gabriela Luisa Krawszuk.

\section{RESUMEN}

Este estudio tiene como objetivo identificar las contribuciones de gestión de documentos al proceso de gestión del conocimiento. Tal enfoque se limita a las prácticas de gestión del conocimiento desarrolladas a partir de la información administrativa contenida en los documentos producidos por la propia organización. Así, se discute cómo tal información puede ser reutilizada para desarrollar el conocimiento organizacional. El método utilizado parte del levantamiento bibliográfico, limitando la selección de libros relacionados a la administración y archivología, y se tiene la gestión del conocimiento como categoría orientadora. Los datos recolectados son analizados por medio de la triangulación entre administración, archivología y gestión del conocimiento. La discusión sigue la lógica deductiva, y después de esa reflexión, se obtiene un artículo de revisión no sistemática que teje los eslabones interdisciplinarios para abordar dicha convergencia. De esta forma, la organización puede extraer 
información confiable a través de sus documentos para contribuir al proceso de toma de decisiones, además de fomentar la innovación y desarrollar una ventaja competitiva. Se plantea que el reúso de la información contenida en los archivos permite que los colaboradores racionalicen las actividades en favor de la eficiencia administrativa. En consecuencia, la sinergia producida por estas actividades agrega valor organizacional.

Palabras clave: Administración; Archivología; Gestión de documentos; Capital intelectual

Organizational knowledge management: archival processing for reuse of administrative information Henrique Machado dos Santos and Gabriela Luisa Krawszuk

\section{Abstract}

This study aims to identify contributions of record management for the knowledge management process. Such an approach is limited to those practices of knowledge management developed from the administrative information contained in records produced by the organization itself. Thus, the discussion is how this information can be reused in order to develop organizational knowledge. The method utilized begins with a bibliographical survey, limiting the selection of books to those related to administration and archival science, and recurs to knowledge management as guiding category. Collected data are analyzed through administration, archival science and knowledge management. The discussion is based on deductive logic, and after this reflection a nonsystematic revision is obtained, that weaves interdisciplinary links to tackle such convergence. This way, the organization can extract reliable information through its records, in order to contribute to the decision-making process, besides fostering innovation and developing competitive advantage. It is assumed that the reutilization of the information contained in the archives allows employees to rationalize activities for administrating efficiency. Consequently, the synergy produced by these activities adds up organizational value.

Keywords: Administration; Archival science; Records management; Intellectual capital 


\section{INTRODUÇÃO}

R egistrar a informação em algum suporte é uma das formas tradicionais Rpara transmitir o conhecimento entre gerações através do espaço/tempo. Sendo assim, o documento, entendido como a informação registrada em suporte, passou a atuar em diversos setores no mundo do trabalho e da pesquisa, consequentemente, tornou-se um importante meio para o desenvolvimento das sociedades.

Com o passar dos séculos, a informação se configurou como um ativo pertinente para as organizações. A moderna gestão exige que a tomada de decisão seja fundamentada em informações e dados concretos, o que torna o trabalho dos gestores mais eficaz e seguro. Logo, é fundamental que as organizações percebam a importância de um sistema para organizar e processar as informações a fim de agregar valor.

Além de considerar a quantidade e a qualidade de informações geradas, é preciso que a gestão da informação organizacional atinja as partes interessadas, e respectivamente, autorizadas, de forma ágil e precisa. Dessa forma, a velocidade com que as informações são disponibilizadas irá acelerar as tomadas de decisão, e consequentemente, gerar vantagem competitiva frente aos concorrentes.

Há de se destacar que a sociedade moderna desperta uma constante necessidade de mudanças e inovações nos produtos e serviços oferecidos pelas organizações. Portanto, a gestão do conhecimento contribui para atender essa demanda ao gerar dinamismo e criatividade, e como consequência agrega valor à organização.

Os constantes avanços das Tecnologias da Informação e Comunicação (TIC) remodelaram os hábitos dos indivíduos com relação à produção, ao armazenamento e ao uso da informação. Por consequência, surge a informação digital, que pode ser facilmente criada, editada, disseminada ou excluída. Tais facilidades motivaram a demanda da sociedade por esses formatos, e assim, transformaram os meios de comunicação.

Com o advento dos computadores surgiram os documentos digitais, que passam a ser produzidos no âmbito das organizações em prol da eficiência administrativa. Os acelerados avanços das TIC também impulsionaram o desenvolvimento de ferramentas para gestão organizacional. Em virtude dessa demanda ocorreu o aumento da produção e da disseminação de documentos e informações digitais. Tal fato desencadeia novas perspectivas e questionamentos em relação à organização do conhecimento e tratamento da informação. 
Neste contexto, a gestão do conhecimento incorpora ferramentas de TIC em suas atividades para facilitar a coleta e o uso do capital intelectual das organizações. $\mathrm{O}$ conhecimento pode ser coletado em diversos tipos de fontes de informação, dentre elas: bases de dados, dicionários, documentos administrativos, enciclopédias, legislação, livros, manuais, normas técnicas, periódicos científicos, entre outros. No entanto, este estudo se limita em abordar as práticas de gestão do conhecimento no âmbito das fontes documentais produzidas pela própria organização.

Inicialmente, as informações administrativas produzidas no decorrer das funções e atividades organizacionais serão registradas em suportes para fixar seus conteúdos, tendo em vista o seu uso a posteriori. Dessa forma, tem-se um documento, que por ser produzido no contexto organizacional, é entendido como um documento arquivístico. Logo, o arquivo torna-se responsável por guardar e disponibilizar os documentos para os gestores, e contribui assim, ao processo de tomada de decisão.

A mesma informação contida nos documentos armazenados em arquivos e que serve para tomar decisões, também poderá ser incorporada no processo de gestão do conhecimento organizacional. Assim, as informações pertinentes serão tratadas e organizadas para reuso a posteriori coadunando no aprendizado organizacional. Tais propósitos ressaltam a necessidade de preservar e garantir acesso contínuo a documentos autênticos no longo prazo, para que assim, a organização disponha de informações confiáveis.

Desta forma, tem-se por objetivo, realizar uma reflexão sobre as contribuições da gestão de documentos para a gestão do conhecimento. Tal ênfase é calcada na coleta de informações administrativas/orgânicas, oriundas dos documentos arquivísticos digitais, e idealmente reutilizadas para desenvolver a base de conhecimento organizacional. Logo, a discussão concentra-se em vislumbrar os possíveis meios para garantir a autenticidade dos documentos da organização, a fim de agregar confiança no reuso de suas informações.

O método utilizado consiste no levantamento bibliográfico de materiais previamente publicados, limita-se assim essencialmente, a seleção de livros e artigos relacionados à Administração e Arquivística/Arquivologia, e tem a gestão do conhecimento como categoria norteadora. Os dados coletados são analisados por meio de uma triangulação entre Administração, Arquivologia e gestão do conhecimento, de modo que essa discussão segue a lógica dedutiva, promovendo um diálogo integrado. Após tal reflexão, obtém-se um artigo de revisão com caráter assistemático e viés descritivo, que tece elos interdisciplinares para abordar uma possível convergência entre a gestão do conhecimento e a gestão de documentos (Gil, 2010: 29; Luna, 1997: 94; Silva e Menezes, 2005: 37; Volpato et al., 2013: 32). 


\section{DA INFORMAÇÃO ORGANIZACIONAL AO DOCUMENTO ARQUIVÍSTICO}

A teoria geral dos sistemas possui uma abordagem totalizante, logo, preconiza que os sistemas não podem ser compreendidos, de forma plena, quando suas partes são analisadas separadamente. Com essa teoria é possível compreender as relações de dependência recíproca das disciplinas envolvidas e os seus níveis de integração (Wittmann e Maehler, 2008: 25). Nessa perspectiva, entende-se o arquivo como um subsistema que contribui para o desenvolvimento das funções e atividades do sistema maior, a organização. Portanto, o documento arquivístico tem dupla face: um subproduto das atividades; e uma fonte informação estratégica.

Os documentos contêm informações valiosas, constituindo um importante ativo ao negócio. Portanto, uma abordagem sistemática da gestão documental é fundamental para que as organizações protejam e preservem os documentos como evidências de suas ações, e assim, possam apoiar atividades subsequentes e tomadas de decisão (ISO, 2016a: 4).

$\mathrm{O}$ ritmo acelerado da sociedade industrial catalisou a produção de grandes massas documentais, cuja conservação total é utópica. Tais documentos consistem em fontes de informação necessárias a administração, as quais que exigem assistência técnica para dar ordem ao caos, e assim, tornar a informação acessível (Cruz Mundet, 1997: 28).

A informação exerce função elementar na organização, visto que influencia quaisquer decisões que são tomadas. No entanto, seu valor e sua pertinência ficam comprometidos caso seja incorreta ou esteja indisponível no momento em que é solicitada (Soares e Salazar, 2005: 127). A precisão da informação é essencial para os gestores, portanto torna-se necessário implementar ações de gestão da informação; e posteriormente, organizar a informação produzida. Assim, toda organização irá produzir informações orgânicas no decorrer de suas funções, que por sua vez, são divididas em atividades-fim e atividades-meio.

As atividades-fim são funções específicas da organização, de natureza técnica ou científica, que estão relacionadas com sua missão. Tais atividades se vinculam às funções formais na exata proporção de suas práticas, o que permite qualificá-las em segmentos conforme desenvolvem atividades similares, mesmo que contenham determinadas diferenças ou especializações (Lopes, 1996: 44; Sousa, 2008: 21).

As atividades-meio são ações necessárias ao cumprimento das atividades-fim, logo, possuem relação indireta. Essencialmente, as atividades-meio compreendem duas ações básicas: uma gerencial e outra burocrática de apoio. As ações gerenciais definem uma política organizacional que sustenta 
suas estruturas conforme as funções indispensáveis que lhe deram origem. Já as ações burocráticas compreendem a gestão de recursos financeiros, humanos, materiais e informacionais. Sendo assim, os documentos administrativos são um subproduto das atividades-meio, as quais estão presentes em todas as organizações. Como consequência, o seu estudo permite compreender a informação documental existente nos arquivos (Lopes, 1996: 44; Sousa, 2008: 21).

Desta forma, as atividades-fim se relacionam aos objetivos primordiais da organização, enquanto as atividades-meio fornecem apoio para que tais objetivos possam ser atingidos. Ambas as atividades geram documentos como subprodutos capazes de atestar as suas ações.

Os documentos arquivísticos não são reunidos artificialmente, mas acumulados pela administração no decorrer de suas funções em prol dos seus objetivos práticos. Portanto, são acumulados contínua e progressivamente. Tal sistemática caracteriza uma coesão espontânea, mas, ao mesmo tempo, estruturada: os documentos arquivísticos são produzidos conforme a necessidade de cumprir as funções organizacionais; mesmo assim, sua acumulação segue uma lógica, de modo que mantêm relações entre si, denominadas organicidade (Jardim e Fonseca, 2008: 126).

A acumulação de documentos arquivísticos orgânicos resultará na origem do arquivo da organização, no qual serão agrupados todos os documentos produzidos ou recebidos no exercício de suas funções, independentemente do seu suporte (Sousa, 2009: 114). Assim, cada organização possuirá o seu arquivo, com os seus respectivos documentos, acumulados organicamente, que carregam consigo o princípio da proveniência.

Com a aplicação do princípio da proveniência é possível constituir o fundo de arquivo, o qual muda a percepção dos documentos, que passam a ser considerados enquanto conjunto, e não individualmente. Assim, o produtor irá reunir os documentos provenientes de uma mesma origem, conforme suas atividades para facilitar a organização e a gestão. Este princípio evita a dispersão e a subjetividade da interpretação dos documentos, pois normalmente, os documentos possuem apenas uma proveniência (Rousseau e Couture, 1998: 84).

Para compreender a acumulação de documentos é necessário entender como as organizações estão estruturadas e como executam as suas funções e atividades (Sousa, 2008: 13). A eficácia do documento arquivístico está relacionada à qualidade e ao rigor dos procedimentos utilizados pela organização produtora. Logo, princípios como a organicidade e a proveniência são essenciais para compreender a composição e a organização do fundo documental; pois consistem em um reflexo das funções e atividades organizacionais. 
As informações necessárias para compreender funções, atividades e demais tarefas de uma organização nem sempre estão registradas. Tradicionalmente, essas informações integram o conhecimento tácito, que está presente na memória dos colaboradores. As funções podem ser identificadas por meio de contratos, estatutos, regimentos, decretos, entre outros documentos referentes à própria organização. Já as atividades por vezes são registradas em organogramas, planos estratégicos e planos de ação, no entanto, isso nem sempre ocorre. Consequentemente, o arquivista deverá recorrer a ferramentas para coletar tais informações, que são essenciais no processo de compreensão da gênese documental (Sousa, 2008: 26).

Idealmente, a estrutura organizacional deve ser constituída com base nos objetivos, na missão, e nas respectivas funções e atividades. Com isso, obtém-se um organograma que retrata a estrutura organizacional, além de apontar as divisões e delimitar os níveis da hierarquia administrativa (Sousa, 2009: 131). E para compreender o contexto de produção documental, deve-se conhecer o seu histórico, especialmente, em relação às suas funções e atividades desenvolvidas. Para tal, torna-se necessário realizar um levantamento de dados (Gonçalves, 1998: 20).

Nessa coleta, o principal dado será a descrição das atividades organizacionais e sua relação com o fluxo de informações implícito nos documentos. No entanto, por vezes não há consciência da vinculação entre as informações e o seu respectivo uso. O trabalho desenvolvido pode gerar níveis de alienação que impeçam a percepção da informação no âmbito organizacional. Deste modo, a informação documental passa, erroneamente, a ser tratada como outro aspecto que não é vinculado às funções e atividades organizacionais (Lopes, 1997: 39).

Tal percepção leva a um distanciamento entre as organizações e os seus arquivos, e torna-se um entrave à eficiência da gestão de documentos e informações. Desta forma, diminui a participação dos profissionais de arquivo no planejamento dos fluxos de processos. E como consequência, os procedimentos de organização, realizados sobre os documentos arquivísticos, passam a satisfazer parcialmente os gestores, de modo a prejudicar a eficiência da organização.

Observa-se que a falta de comunicação entre Administração e Arquivologia, é uma deficiência que se reflete diretamente nas organizações, e por consequência, dificulta a compreensão do seu funcionamento. Logo, essa incongruência interfere em questões como, por exemplo, detecção de problemas, busca por soluções e demais tomadas de decisões (Sousa, 2009: 145).

Ao romper o diálogo interdisciplinar, perde-se a sinergia da relação entre Administração e Arquivologia, e isso pode acarretar em perdas catastróficas, 
do ponto de vista estratégico e financeiro. Com a cisão dessas áreas, perde-se uma oportunidade para potencializar o reuso da informação orgânica na busca por competitividade.

Observa-se que a Administração possui diversos procedimentos metodológicos para realizar o diagnóstico organizacional a fim de melhorar a sua eficiência. Sendo assim, a pesquisa arquivística não irá intervir no funcionamento da organização, seu objetivo é entender a estrutura, as atribuições e as atividades. Por vezes, esses conhecimentos são construídos de forma separada em virtude da falta de comunicação e de reconhecimento entre as áreas (Sousa, 2008: 27).

Logo, a proposição para as áreas (Administração e Arquivologia) é o diálogo interdisciplinar, no qual não haverá interferência, e sim, retroalimentação. Tal relação otimiza a gestão de documentos e informações, e consequentemente, irá aprimorar o processo de tomada de decisão. Além disso, tal sincronia permite avançar no âmbito da gestão da informação, e atingir um novo estágio, a gestão do conhecimento, para então transformar a organização em um ambiente de aprendizado contínuo.

\section{FundAMENTOS DA GESTÃO DO CONHECIMENTO}

O processo informacional das organizações consistia em coletar, armazenar e distribuir informações. Entretanto, após receber influência da reengenharia e do redesenho de processos, passou a incorporar questões como o uso da informação, a aprendizagem de quem a utiliza e o compartilhamento. Assim, com a evolução das atividades do processo de negócio surge o uso da informação como um potencial estratégico para a organização. Dessa forma, ressalta-se que o processo de negócio não se manteve apenas voltado à informação, evoluiu, e passou a vislumbrar ao conhecimento gerado (De Sordi, 2008: 3 ).

A gestão do conhecimento consiste em uma área de convergência entre a tecnologia da informação e a Administração. Logo, está diretamente relacionada com os processos utilizados para criar, disseminar e utilizar o conhecimento a fim de alcançar os objetivos organizacionais (Rosini e Palmisano, 2003: 137). Assim, tem-se um conjunto de processos, práticas e procedimentos para identificar, registrar e gerenciar o conhecimento das pessoas, e consequentemente, possibilitar seu reuso no ambiente organizacional (Santos, 2009: 191).

Houve um tempo em que as organizações preocupavam-se somente com números e resultados obtidos através dos colaboradores, e ainda existem gestores que prezam somente pelo resultado, o que acarreta em um ambiente sem 
motivação e exaustivo. Entretanto, outros, optam por uma organização com um ambiente voltado a desenvolver o capital intelectual, onde consideram o estado de espírito de todos os envolvidos na área interna e externa. É com base nessas premissas que a gestão do conhecimento torna-se cada vez mais importante para as organizações, pois é capaz de fazer a intermediação entre os conhecimentos que serão transmitidos e adquiridos pelos colaboradores.

Observa-se que o conhecimento pode ser classificado em duas categorias: explícito e tácito. O conhecimento explícito é o conjunto de dados ou informações que estão registrados e são passíveis de serem utilizados, de modo que podem ser facilmente processados, armazenados e disseminados. Já o conhecimento tácito é de qualidade pessoal e sua utilização ocorre por meio de experiências, valores e demais relacionamentos entre os indivíduos (Silva Filho e Silva, 2005: 28). O conhecimento tácito é construído pelos colaboradores da organização de forma coletiva, se aplica no contexto de interação dos sujeitos por meio de intervenções corretas entre si (Araújo, 2014: 134).

Nota-se que os benefícios da gestão do conhecimento são intangíveis. Por isso, organizações de grande porte demandam atenção especial para esse fator. Logo, é possível criar processos de desenvolvimento e competência mais ágeis, expandir a inovação, a criatividade e o conhecimento através de técnicas colaborativas; além de gerir o capital intelectual de forma estruturada. Ao implementar a gestão do conhecimento, a organização passa a adquirir velocidade no desenvolvimento, e consequentemente, aumentará a sua vantagem competitiva.

$\mathrm{Na}$ era da sociedade do conhecimento, as organizações não podem negligenciar os conceitos e a implementação da gestão do conhecimento, em virtude sua importância estratégica, tanto para agilizar os processos, quanto para tomar decisões (Schuster e Silva Filho, 2005: 54). O capital intelectual torna-se um diferencial competitivo, e assume a forma de um ativo intangível, consequentemente, as organizações que tratam esse conhecimento ganham valorização frente às demais (Luz, 2010: 31).

Observa-se que o conhecimento consiste na maior riqueza das organizações, e possibilita que os gestores tomem decisões de forma rápida e precisa. Além disso, o conhecimento potencializa a criatividade e a inovação, as quais geram resultados à organização (Schuster, Silva Filho e Calil, 2005: 81). Tais resultados são capazes de fazer com que colaboradores consigam se beneficiar de experiências anteriores para aperfeiçoar os processos existentes e alavancar o crescimento do negócio por meio da inovação.

Desta forma, as equipes de trabalho passam a ter acesso a conhecimentos e informações necessários para desenvolver, criar e inovar, e assim, acelerar a elaboração de novas estratégias, produtos ou serviços. Portanto, organizações 
que compartilham o conhecimento com seus colaboradores são capazes de eliminar gargalos, e consequentemente, aumentar a produtividade e a competitividade. Assim, ressalta-se a importância de transformar o conhecimento em competitividade e capacidade de inovar:

O diferencial competitivo das organizações é o conhecimento. A criação e a difusão do conhecimento são a chave competitiva para o sucesso das organizações. O desafio porém, é transformar a busca e a troca de conhecimentos em produtividade, qualidade, métodos, processo e produtos inovadores. Interessa gerar e disseminar o conhecimento, e produzir inovações. A inovação é vista como um dos elementos determinantes da competitividade empresarial. Na verdade, a vantagem competitiva da organização decorre de sua capacidade de criar e inovar sempre. (Silva Filho e Silva, 2005: 24)

A gestão do conhecimento consiste em uma abordagem sistemática para garantir a plena utilização dos recursos organizacionais. Para tanto, faz-se uso de uma base de conhecimentos, combinada com habilidades individuais, competências e ideias inovadoras para aumentar a eficiência e a eficácia da organização (Dalkir, 2005: 2).

Ressalta-se que a inovação está diretamente relacionada à posse e ao uso do conhecimento. Logo, as organizações que possuem maior capacidade gestão de conhecimento não são, necessariamente, as que têm o melhor desempenho (Darroch, 2005: 111).

Desse modo, observa-se a pertinência da gestão do conhecimento, bem como do seu uso adequado, para as organizações contemporâneas que buscam manter competitividade por meio da constante inovação. Consequentemente, a valorização do capital intelectual proporciona uma nova perspectiva organizacional, com foco nas pessoas e seus processos relacionados.

\section{GESTÃo DO CONHECIMENTO: UM DiÁLOGO ENTRE A ADMINISTRAÇÃO E O ARQUIVO}

As organizações são naturalmente produtoras de conhecimentos e podem reutilizá-los tanto para melhoria de serviços, quanto para eficiência administrativa. No que tange ao conhecimento explícito, cabe ressaltar que os documentos produzidos organicamente (ditos documentos arquivísticos), são fontes de informações elementares, pois fornecem dados e informações sobre decisões tomadas do passado. Com isso, é possível realizar levantamentos de dados e comparações a fim de compreender o impacto e a assertividade das decisões. 
Ao considerar esse ciclo de retroalimentação, entre Administração e Arquivologia, é preciso aliar a preservação à competitividade, de modo que as ações do arquivo não interfiram de forma prejudicial na gestão. Além disso, surge a necessidade de equilibrar a confiabilidade e o acesso, para que assim, as informações sejam acessadas apenas pelos indivíduos autorizados. Ressalta-se que o diálogo entre arquivo e administração poderá ser reforçado por normas que enfatizam a gestão de documentos com viés organizacional, dentre elas: ISO 15489 e a série ISO 30300.

A ISO 15489-1:2016 define conceitos e princípios que agregam valor às informações organizacionais, compreendendo assim: criação, captura, gestão, controle, políticas, atribuição de responsabilidades, monitoramento, treinamento, análise do contexto de negócio, identificação de requisitos, metadados necessários e sistemas de informação. Dessa forma, é possível integrar a gestão de documentos aos sistemas de negócios (ISO, 2016a: 1).

Já a ISO 15489-2:2001 consiste em um guia de implementação da ISO 15489-1 para profissionais e responsáveis pela gestão da informação nas organizações. Fornece uma metodologia que facilitará a implementação, bem como uma visão geral dos processos e fatores que devem ser considerados para cumprir a norma. Seu uso é facultativo e complementar, de modo que expande tópicos da ISO 15489-1, traz as etapas a serem seguidas pelo sistema de gestão documental, com objetivo de alcançar os resultados previstos (ISO, 2001: 1).

A ISO 30300:2016 estabelece termos, definições e objetivos para uso dos sistemas de gestão de documentos, ademais, orienta como implementar, manter e aperfeiçoar estes sistemas. Todas as organizações produzem documentos arquivísticos no decorrer de suas atividades para cumprir os objetivos organizacionais. Logo, esta norma define políticas, objetivos e estrutura necessária aos sistemas de gestão de documentos, conforme os requisitos da organização (ISO, 2016b: 1).

Ressalta-se que a série ISO 30300:2016 consiste em uma norma geral, e têm subordinadas a si: a ISO 30301 que estabelece os requisitos dos sistemas; a ISO 30302 que oferece orientações para implementação; a ISO 30303 que oferece requisitos a serem cumpridos pelo organismo responsável pela auditoria e certificação; e a ISO 30304 que contempla um guia de avaliação dos sistemas.

\section{Reuso da informaçáo administrativa}

As organizações produzem informações diariamente em virtude de suas atividades-fim e meio, isso aduz a existência de um fluxo contínuo para geração de conhecimentos. Doravante, esse capital intelectual pode ser otimizado por meio do reuso de documentos e informações, de modo a facilitar ações rotineiras ou servir de base empírica para uma autocrítica organizacional. 
Em geral, as organizações exigem informações permanentes, de modo que o seu armazenamento em sistemas de arquivos é consequência lógica dessa necessidade. Portanto, as organizações devem compreender a questão informacional como um problema complexo e global. Primeiramente, as informações apoiam o uso administrativo, e posteriormente, são preservadas em longo prazo, podendo ser transformadas em conhecimento e reutilizadas (Arévalo Jordán, 2012: 19).

Tais informações são cruciais para as organizações, pois é por meio delas que inúmeros relatórios e balanços serão gerados. Assim, os gestores podem tomar decisões com base em informações confiáveis, que lhes retornam resultados concretos, então otimizados pelo avanço tecnológico. No entanto, esses relatórios devem aliar a complexidade da informação à facilidade de compreensão, para que assim, gestores e diretores os utilizem de forma rápida e precisa apesar da constante mudança (criação, edição e exclusão) de dados na organização.

Observa-se que a gestão de documentos deve ir além do ato de registrar a informação em um suporte, e desenvolver um planejamento. Tal ação torna-se mister, pois as organizações dispõem de quantidades exacerbadas de documentos, que podem ser gerenciadas por ferramentas de TIC para facilitar as tomadas de decisão. Assim, a TIC aperfeiçoa a busca e a recuperação das informações, e pode garantir qualidade e precisão, além de proporcionar um ambiente confiável para armazenamento (Moreno, 2008: 73).

Com o advento da sociedade da informação, as organizações passam a perceber a importância dos seus arquivos. Assim, a gestão de documentos traz uma série de benefícios ao ambiente organizacional, como, por exemplo: a possibilidade de identificar informações de forma ágil, a padronização dos métodos de arquivamento, e a eliminação de ambiguidades a fim de otimizar o acervo e demais setores da organização.

A informação produzida no âmbito administrativo pode assumir significados que vão além da realidade jurídico-organizacional, de testemunho ou de fonte histórica. Para tal, as informações geridas pelo arquivo devem ser aliadas com informações que advém de outros campos científicos (Bellotto, 2006: 271). Uma convergência entre gestão de documentos e gestão do conhecimento permite a racionalização das informações produzidas no contexto organizacional. Assim, ambas as áreas serão contempladas com benefícios mútuos, dentre estes, destacam-se: a redução, racionalização e organização da massa documental/informacional produzida; e o aumento da qualidade da informação gerida.

Do ponto de vista documental, a gestão do conhecimento visa garantir que as informações produzidas nas relações da organização com seus clientes, 
fornecedores, ou outros, sejam devidamente registradas e documentadas. Tal registro independe do suporte (analógico ou digital), logo, deve-se assegurar a sua permanência no longo prazo, a capacidade de recuperação e o uso eficiente do conhecimento (Múnera Torres e Pabón Ángel, 2002: 32).

O conhecimento não é sinônimo de informação, embora possa existir uma relação de mediação entre ambos. A informação é utilizada para referenciar o que está de certa forma, disperso e desordenado. Entretanto, o conhecimento consiste nas informações que foram devidamente apropriadas e sistematizadas, ou seja, é fruto da aprendizagem (Bartalo, 2008: 95).

O conhecimento adequado proporciona tomadas de decisão eficazes, consideradas indispensáveis para as organizações se adequarem a uma sociedade em constante transformação (Tonini, 2006: 23). Sendo assim, o nível de qualidade da informação é fundamental para se utilizar o conhecimento de forma segura e desenvolver um diferencial competitivo. Logo, a qualidade do processo de transformar informações em conhecimentos irá influenciar no sucesso ou no fracasso das tomadas de decisão (Silva, 2003: 30).

Há gestores que desconhecem a importância aos arquivos, os quais são vistos como uma unidade onde apenas se acumulam documentos. Nesse caso, tais arquivos tornam-se desordenados e mal administrados, além disso, os funcionários responsáveis pela gestão documental, por vezes, não possuem devida capacitação para exercer tal função. Logo, têm-se arquivos improvisados, sem as condições ideais para acondicionamento, de modo que a documentação divide espaço com os demais setores de trabalho.

Os arquivos desorganizados, compostos por documentos vitais e inúteis, causam transtornos para as organizações, em virtude da dificuldade para consultar a documentação. Tal desorganização dificulta o processo de tomada de decisão administrativo, e por vezes, decisões equivocadas podem ser tomadas com base em dados desatualizados. Além disso, a perda de documentos irá causar diversos prejuízos à organização, dentre estes: insatisfação do cliente, perda de mercado e perda de ações judiciais por não possuir ou não localizar a documentação comprobatória.

A gestão de documentos eficiente requer que a informação seja localizada com precisão e rapidez. Da mesma forma, os custos relacionados e o espaço de armazenamento, manutenção e conservação dos documentos precisam ser otimizados. Assim, os documentos não devem ser preservados por períodos de tempo que extrapolam o cumprimento de suas atividades, salvo os casos em que possuírem valor probatório, de pesquisa e outros de interesse social ou organizacional (Schellenberg, 2006: 68).

Já com o crescente acúmulo de documentos digitais nas organizações, torna-se necessário o uso de instrumentos para classificar os conteúdos criados 
ou recebidos. Logo, a taxonomia pode ser usada para definir categorias de assuntos (De Sordi, 2008: 150). Assim, os sistemas arquivísticos corroboram com essa visão, pois capturam os documentos, que são evidências das atividades da organização. Tais sistemas se diferenciam dos demais em virtude de suas capacidades para gerenciar o conteúdo e a estrutura dos documentos, promover o acesso contínuo, e manter o elo entre os documentos e as atividades (Castro, Castro e Gasparian, 2007: 93).

A gestão de documentos deve contemplar as funções de organização e racionalização dos documentos tendo em vista a administração e os demais usuários. Logo, o tratamento preconizado pela Arquivística é entendido como uma atividade contínua, que contempla todo o ciclo de vida dos documentos (Heredia Herrera, 1998: 33). A principal finalidade dos arquivos consiste em apoiar a Administração, para isso, devem gerir a massa documental produzida a fim de facilitar o reuso da informação. A gestão de documentos eficiente requer atenção em toda a sua custódia: desde a produção nos arquivos correntes, perpassando a avaliação, até o seu recolhimento ao arquivo permanente.

Com a Indústria 4.0, a informação é tida como um diferencial no mercado competitivo. Assim, o arquivo quando organizado conforme as normas arquivísticas gera competitividade, uma vez em que a informação ficará disponível para o gestor tomar decisões precisas e ágeis. Desta forma, a correta gestão de documentos contribui para melhoria do processo de busca e recuperação da informação nas organizações. Além disso, a informação digital, quando organizada, proporciona dinamismo frente aos documentos analógicos.

Há uma tendência de aumento da velocidade nas mudanças do mercado e nas exigências dos clientes. Logo, as organizações precisam agilizar os processos de tomada de decisão. Para tanto, faz-se necessário o uso de ferramentas de busca para auxiliar o gestor na recuperação de documentos e informações digitais. A agilidade dessa busca irá otimizar os fluxos de trabalho, e tem por consequências diretas, o aumento da produtividade e da satisfação dos clientes.

Observa-se que a gestão de documentos digitais dependente de sistemas informatizados capazes de controlar o ciclo de vida, manter as suas características e a sua organicidade. Dessa forma, estima-se assegurar a autenticidade dos registros custodiados (Silva, 2017: 14). A autenticidade dos documentos digitais deve ser evidenciada por meio de tecnologias e procedimentos administrativos que assegurem a sua identidade (data/hora e responsáveis pela produção, indicação de anexos, nome da pessoa física ou jurídica que produz ou recebe, entre outros) e integridade (completo e inalterado) (InterPARES 2 Project, 2007: 7). 
A garantia de autenticidade torna-se um pré-requisito para que a informação contida nos arquivos possa ser reutilizada na organização, por meio da gestão do conhecimento. Há um risco incomensurável de se utilizar informações dúbias no processo de tomada de decisão, seus efeitos são inimagináveis, e por vezes, irreversíveis. Portanto, surge a necessidade de implementar sistemas de informação confiáveis.

A idoneidade dos sistemas de gerenciamento arquivístico consiste, primeiramente, em limitar o acesso ao sistema, criar regras de workflow, senhas de acesso, dentre outros privilégios. Nesse sentido, será possível integrar procedimentos administrativos e arquivísticos, e definir no workflow quais ações podem, e como, devem ser realizadas. Posteriormente, torna-se necessária a verificação por meio de uma trilha de auditoria que registre as intervenções nos documentos, como, por exemplo, modificar, apagar, acrescentar ou visualizar. Dessa forma, será possível reafirmar o que foi definido a priori, a fim de comprovar a autenticidade (Rondinelli, 2005: 65).

Com um sistema de arquivos confiável, será possível garantir a autenticidade dos documentos, e consequentemente, as suas informações poderão ser reutilizadas pela organização através da gestão do conhecimento. Nesse processo, a informação contida nos arquivos evolui para um novo patamar, torna-se uma informação estratégica da organização, e passa a influenciar nas tomadas de decisões.

\section{Da gestáo tecnológica à informaçâo estratégica}

Desenvolver uma estratégia organizacional para o recurso informação/conhecimento compreende: definir os tipos de informação/conhecimento que serão priorizados; identificar a sua contribuição; e elencar as atividades de gestão do conhecimento que serão enfatizadas. No entanto, ressalta-se que as atividades escolhidas no processo de gestão do conhecimento variam conforme a estratégia e o contexto organizacional (De Sordi, 2008: 92).

Tradicionalmente o tratamento de dados era realizado para obter relatórios e fazer análises. No entanto, tal preocupação não se restringe somente a isso, ou seja, atualmente as TIC fomentam a gestão da informação organizacional. Logo, a inovação tecnológica torna-se necessária para otimizar e aperfeiçoar os processos, de modo a tornar a organização ágil, produtiva e competitiva.

Com isso, a busca por flexibilidade é primordial para as organizações tendo em vista a necessidade de adaptação. Para tanto a organização deve analisar o cenário (macro e micro) no qual está inserida para identificar as necessidades dos clientes a fim de melhorar a qualidade e a relação de custo/benefício dos 
seus produtos e serviços. Assim, a busca por flexibilidade tornará o ambiente interno inspirador aos seus colaboradores.

As organizações estão inseridas em um ambiente dinâmico que exige, cada vez mais, uma postura flexível. Portanto, devem compreender esse contexto para resolver questões como o crescimento do mercado, a capacidade de expansão, a elaboração de produtos, a melhoria da qualidade de produtos e serviços, a redução de custos e a satisfação dos clientes. Munidos dessas informações, os gestores poderão traçar estratégias para garantir a sua permanência competitiva. Esse ambiente favorece as organizações que possuem dinamismo e flexibilidade, que fomentam a criatividade e investem na melhoria da capacidade de aprendizado (Sonaglio, Santos e Marion Filho, 2008: 135).

O ambiente organizacional está em constante transformação, consequentemente, torna-se essencial buscar vantagem competitiva em relação aos concorrentes. Logo, para se obter tal vantagem é necessário que a organização priorize a criatividade e a inovação, tendo em vista a capacidade de aumentar os níveis da competitividade para manter-se a frente no segmento de mercado em que atua. Trata-se de uma sistematização do conhecimento capaz de gerar um diferencial competitivo.

O ambiente para gestão do conhecimento subentende desenvolver um contexto organizacional favorável. Isso inclui questões como a disponibilização de softwares que possam contribuir com as atividades e tarefas que integram tal processo. Há diversos softwares que disponibilizam funcionalidades variadas, que se adequam conforme cada tipo de atividade. Paralelamente a essas ferramentas, há altos custos relacionados na sua implementação, com isso, tais investimentos tornam-se um desafio significativo à organização (De Sordi, 2008: 4).

Portanto, é crucial que a organização qualifique os gestores e automatize os processos, com objetivo de facilitar a recuperação da informação. Logo, o controle eficaz pode ser realizado por meio de um sistema de gestão, o qual consiste em um conjunto de softwares para auxiliar no crescimento organizacional. Entretanto, há casos em que os gestores podem demonstrar resistência para adquirir esses sistemas.

Dentre as principais alegações para tal óbice, está o preço elevado dos softwares a serem adquiridos, incutindo uma visão de aumento de gastos na organização. Para tanto, é preciso que os gestores pensem no médio e no longo prazo, a fim de compreender que haverá retorno do investimento em sistemas informatizados. A ressalva a ser feita é que tal retorno dependerá do uso adequado dos sistemas, sendo assim, ressalta-se a pertinência da qualificação dos colaboradores em relação aos sistemas informatizados que a organização utiliza. 
A finalidade de um sistema de informação deve ser voltada a utilização da informação e aos resultados obtidos pelos usuários. A função primordial desse sistema é a capacidade da informação modificar as atividades efetuadas pelo usuário. Logo, os sistemas de informação devem ser orientados ao usuário (Le Coadic, 2004: 38). Nesse caso, os conhecimentos são disponibilizados ao usuário interno da organização, com a finalidade de melhorar os serviços prestados, reduzir custos relacionados e evitar o retrabalho.

A gestão do conhecimento aplicada as plataformas digitais se responsabiliza não apenas pelas informações contidas em seus ambientes, mas também pelas contidas na rede off-line, isto é, conhecimento tácito que precisa ser externalizado. Para garantir o fluxo de conteúdo e fortalecer uma rede sólida é necessário incentivar o compartilhamento em formato distribuído, garantido o fluxo de conversação e troca de informações entre diversas pessoas e canais que possuem conhecimento acumulado. Estes, com habilidades e informações distintas, mas com interesses em comum, potencializam uma rede, disseminando ideias, produzindo e compartilhando conteúdo e construindo novos negócios e saberes. (Luz, 2015: 61)

A gestão do conhecimento deve ser compreendida como um investimento, o que justifica os gastos com os softwares e a capacitação de pessoas. A organização como um todo deverá ser contemplada, assim, destaca-se que no setor de arquivo surge a necessidade de definir uma política que vislumbre o reuso da informação. Portanto, a gestão do conhecimento deve fazer parte da estratégia de negócio das organizações para gerar vantagem competitiva.

Tendo em vista que a principal finalidade dos arquivos consiste em apoiar a Administração, suas ações concentram-se na utilização racional e na disponibilização das informações custodiadas (Paes, 2004: 20). Nesse sentido, o conhecimento organizacional deve ser transferido, no entanto torna-se necessário controlar sua difusão para não prejudicar os objetivos estratégicos. Essa restrição se aplica aos conhecimentos relativos à vantagem competitiva da organização (Silva Filho e Silva, 2005: 31).

As tecnologias da informação têm o poder de estabelecer novos mercados de atuação para as organizações, assim como conectá-las ao mundo por meio da troca de informações. Tais possibilidades de interação foram proporcionadas pela economia moderna e pelo advento da globalização. No entanto, a mesma globalização que reduz distâncias, também poderá disseminar dados sigilosos de uma organização, fazendo eclodir uma série de estardalhaços sobre a mesma.

A organização possui responsabilidade sobre os dados de clientes, logo, deve manter o sigilo interno, para que esses dados somente sejam disponibilizados aos indivíduos autorizados. A quebra do sigilo de dados dos clientes 
poderá abalar a confiança em relação à organização, e ocasionar processos judiciais. Sendo assim, pode-se afirmar que manter tal sigilo é um meio tanto para garantir competitividade ao negócio, quanto para reafirmar o compromisso da organização com sua missão e seus valores.

As organizações devem elaborar políticas de segurança da informação para proteger seus dados. Logo, deve-se atentar para questões como, por exemplo, as redes de intranet e internet, bem como as rotinas backup. Além disso, deve-se verificar a eficácia do armazenamento em nuvem, visto que tais serviços são prestados por terceiros, de modo que a organização delega as ações de custódia, embora continue sendo a responsável pelos dados.

Por vezes a organização deverá manter sigilo em relação às suas atividades internas, isso pode compreender: a fórmula de seus produtos, técnicas utilizadas, processos de fabricação, parcerias firmadas, fornecedores, materiais e estratégias de negócios. Para tanto, torna-se essencial firmar um contrato de confidencialidade, o qual corresponde ao instrumento jurídico que protege segredos de natureza industrial ou comercial. Este contrato tem por objetivo assegurar que tais informações serão mantidas em sigilo.

Além disso, a organização necessita gerenciar possíveis riscos, treinar a equipe e estabelecer níveis de acesso à informação para reforçar a segurança. Portanto, somente os colaboradores autorizados devem ter acesso aos dados pessoais de clientes e aos segredos de negócio. A ausência de procedimentos de segurança da informação pode desencadear uma série de invasões e quebras de sigilo indevido, capazes de gerar diversos prejuízos para as organizações. Logo, o vazamento de dados pessoais dos clientes irá gerar uma imagem negativa da organização.

Observa-se que as organizações devem investir tanto em tecnologias adequadas, quanto na capacitação de seus colaboradores, tendo por resultado o aumento da eficiência e mitigação das vulnerabilidades. Compete aos gestores, definir diretrizes sobre a segurança da informação, de modo que deleguem uma série de responsabilidades e rotinas aos colaboradores. Entretanto, caso essas diretrizes não sejam cumpridas, devem ser aplicadas as penalidades cabíveis.

$\mathrm{Na}$ era da sociedade da informação, o ser humano torna-se um elemento-chave e passa a atuar como um diferencial competitivo nas organizações. Assim, com o foco na valorização das pessoas, os grupos de indivíduos ganham autonomia na tomada de decisão, consequentemente essa nova perspectiva favorece o trabalho criativo e a inovação (Wittmann e Maehler, 2008: 30). Tais questões influenciam até mesmo na seleção de pessoas, tendo em vista que: o trabalho intelectual é predominante na era pós-moderna; logo a proatividade torna-se essencial. Isso se contrapõe à reatividade advinda do período industrial, que era voltado ao trabalho mecânico e repetitivo. 
Há uma estreita relação da gestão do conhecimento com as pessoas e suas habilidades, por conseguinte ressalta-se que a capacidade humana sempre será o bem mais valioso que a humanidade possui, e o único capaz de criar e transformar (Ponjuán Dante, 2015: 214). Dessa forma, o capital intelectual advindo dos colaboradores tornar-se um dos principais ativos organizacionais, e consequentemente, reforça a pertinência de abordagens sistêmicas que considerem o gerenciamento de pessoas, documentos, competências e conhecimentos.

\section{Considerações Finais}

Ao refletir sobre as convergências entre Administração e Arquivologia, observou-se a possibilidade de coletar e reutilizar as informações orgânicas, registradas na forma de documentos arquivísticos, para fomentar a gestão do conhecimento organizacional. Logo, há necessidade de garantir a autenticidade desses documentos para que os colaboradores possam utilizar suas respectivas informações de forma confiável.

Os documentos são produzidos pelas organizações para cumprir as funções definidas em sua missão. Portanto, os documentos arquivísticos consistem, essencialmente, em um subproduto da Administração, e sua produção é dotada de características como, por exemplo, naturalidade, organicidade e proveniência. A produção e acumulação de documentos, no decorrer das atividades-fim e meio, dá origem aos arquivos, de modo que o conjunto documental passa a ter um valor agregado maior do que a soma de suas unidades. Logo, a gestão de documentos visa constituir um sistema de arquivos para otimizar o processo de busca e recuperação das informações orgânicas.

A informação registrada, na forma de documento, consiste em uma fonte de conhecimento explícito e possibilita que a organização produtora possa aprender com os seus erros e acertos. Para tanto, é preciso garantir o caráter de precisão e autenticidade da informação documental, para que essa possa ser transformada em conhecimento, e consequentemente, possibilitar o reuso em prol da eficiência administrativa.

A informação contida nos documentos arquivísticos possui potencial estratégico para as organizações. Para obter tal proveito, é preciso que a gestão de documentos/informações evolua ao nível da gestão do conhecimento. Dessa forma, o reuso da informação organizacional poderá melhorar o processo de tomada de decisão, reduzir custos relacionados, evitar o retrabalho, estimular a criatividade, fomentar a capacidade de inovação e aprimorar os serviços prestados. Como resultado disso, a organização irá aumentar a sua vantagem competitiva, firmando-se no mercado. 
A moderna burocracia administrativa produz significativa quantidade de documentos e informações que necessitam ser armazenados em sistemas de custódia confiável. Os conhecimentos adquiridos pela organização também necessitam de tal confiança, logo, a convergência com os sistemas para gestão de documentos possibilita racionalizar a massa documental e garantir a autenticidade de informações pertinentes.

As organizações, de maneira geral, estão inseridas em um ambiente dinâmico, fato que aumenta a competitividade e gera a busca por conhecimentos e estratégias de negócio para garantir a sua perenidade. De tal forma, ocorre uma reformulação por meio da gestão do conhecimento, assim, a organização, disponibiliza conhecimentos para ensinar, e paralelamente, coleta conhecimentos para aprender. Ou seja, há um ciclo de retroalimentação entre a organização e os seus colaboradores, no qual ambos produzem, disponibilizam e utilizam conhecimentos.

Observa-se que a gestão de documentos, na figura do arquivo, visa organizar, racionalizar e disponibilizar documentos arquivísticos autênticos aos colaboradores para satisfazer as necessidades administrativas. Os mesmos documentos possuem informações estratégicas que podem ser transformadas em conhecimento e assim fomentar o ciclo de aprendizagem organizacional. Os conjuntos documentais fornecidos pelo arquivo são capazes de demonstrar o histórico de determinados investimentos ou tomadas de decisões, e os gestores podem analisá-los por meio de ferramentas de diagnóstico administrativo.

A disponibilização de informações e conhecimentos deve ser orientada aos usuários locais, ou seja, os colaboradores da organização. Tal restrição consiste em proteger as estratégias de negócio e a vantagem competitiva, logo, somente indivíduos autorizados devem ter acesso às informações. Assim, deve-se investir em segurança da informação tanto na gestão de documentos, quanto na gestão de conhecimento, para proteger a organização contra vazamento de informações ou potenciais invasores. Neste cenário, observa-se que a correta gestão e o compartilhamento adequado de informações e conhecimentos tornam-se fundamentais para que a organização possa se firmar no mercado em que atua.

Defende-se uma gestão organizacional sistêmica, embasada em normas internacionais e padrões amplamente aceitos pela literatura da Administração e da Arquivologia. Entende-se a organização como um sistema maior no qual a gestão de documentos se insere como um subsistema, responsável por orientar os fluxos de informação. O documento arquivístico constitui um subproduto das funções e atividades organizacionais, de modo que a interdisciplinaridade entre Administração e Arquivologia fomentará a gestão 
do conhecimento. Dessa forma, é possível gerar conhecimento confiável capaz de sedimentar a inteligência competitiva da organização. Entretanto, tal abordagem carece de metodologia específica.

Por fim, ressalta-se que as práticas de Administração e Arquivologia se coadunam nas organizações, formando uma sinergia capaz de racionalizar as ações de ambas as áreas. Logo, este estudo contribui para clarificar os conceitos básicos da gestão do conhecimento e traçar diálogos interdisciplinares para incorporar a gestão de documentos. A gestão do conhecimento é suficientemente difundida no âmbito da Administração, entretanto, na Arquivologia ainda carece de estudos mais profundos para apontar e discutir sobre o lócus de sua prática.

\section{REFERÊNCIAS}

Araújo, Carlos Alberto Ávila. 2014. Arquivologia, Biblioteconomia, Museologia e Ciência da Informação: o diálogo possivel. Brasília: Briquet de Lemos.

Arévalo Jordán, Víctor Hugo. 2012. "Las instituciones archivísticas". Revista de la Biblioteca y Archivo Histórico de la Asamblea Legislativa Plurinacional 19 (6): 17-28. http://www.revistasbolivianas.org.bo/pdf/fdc/v6n19/n19_a04.pdf

Bartalo, Linete. 2008. "A importância das estratégias de estudo para uma aprendizagem mais significativa na área de arquivologia", em Gestão em arquivologia: abordagens múltiplas, organizado por Linete Bartalo e Nádina Aparecida Moreno, 89118. Londrina: Eduel.

Bellotto, Heloísa Liberalli. 2006. Arquivos permanentes: tratamento documental. 4a. ed. Rio de Janeiro: Editora FGV.

Castro, Astréa de Moraes e, Andresa de Moraes e Castro, e Danuza de Moraes e Castro Gasparian. 2007. Arquivos: físicos e digitais. Brasília: Thesaurus.

Cruz Mundet, José Ramón. 1997. "La gestión de documentos en el Estado español: balance y perspectivas". Métodos de información 17-18 (4): 28-31. http://eprints.rclis.org/4842/1/1997-17-28.pdf

Dalkir, Kimiz. 2005. Knowledge Management in Theory and Practice. Amsterdam: Elsevier Inc. https://dianabarbosa.files.wordpress.com/2009/03/knowledge-management-kimiz-dalkir.pdf

Darroch, Jenny. 2005. "Knowledge management, innovation and firm performance". Journal of Knowledge Management 9 (3): 101-115. https://doi.org/10.1108/13673270510602809

De Sordi, José Osvaldo. 2008. Administração da informação: fundamentos e práticas para uma nova gestão do conbecimento. São Paulo: Saraiva.

Gil, Antonio Carlos. 2010. Como elaborar projetos de pesquisa. 5a. ed. São Paulo: Editora Atlas. 
Gonçalves, Janice. 1998. Como classificar e ordenar documentos de arquivo. São Paulo: Arquivo Público do Estado de São Paulo.

Heredia Herrera, Antonia. 1998. "El debate sobre la gestión documental”. Métodos de información 22-23 (5): 30-36. https://core.ac.uk/download/pdf/11877283.pdf

ISO (International Organization for Standardization). 2001. ISO 15489-2. Information and documentation - Records management Part 2: Guidelines [Technical Report]. Geneva: ISO.

ISO. 2016a. ISO 15489-1. Information and documentation - Records management Part 1: Concepts and principles. Geneva: ISO.

ISO. 2016b. ISO 30300. Information and documentation: Management systems or records-Fundamentals and vocabulary. Geneva: ISO.

InterPARES 2 Project (International Research on Permanent Authentic Records in Electronic Systems). 2007. A elaboração e a manutenção de materiais digitais: diretrizes para indivíduos. Tradução: Arquivo Nacional do Brasil e Câmara dos Deputados. http://www.interpares.org/ip2/display_file.cfm?doc=ip2_creator_guidelines_ booklet--portuguese.pdf

Jardim, José Maria e Maria Odila Fonseca. 2008. “Arquivos”, em Introdução às fontes de informação, 2a. ed., organizado por Bernadete Campello e Paulo da Terra Caldeira, 121-139. Belo Horizonte: Autêntica Editora.

Le Coadic, Yves-François. 2004. A ciência da informação. 2a. ed. Brasília: Briquet de Lemos.

Lopes, Luís Carlos. 1997. A gestão da informação: as organizações, os arquivos e a informática aplicada. Rio de Janeiro: Arquivo Público do Estado do Rio de Janeiro.

Lopes, Luís Carlos. 1996. A informação e os arquivos: teorias e práticas. Niterói: Eduff.

Luna, Sergio Vasconcelos de. 1997. Planejamento de pesquisa: uma introdução. São Paulo: Educ.

Luz, Charlley. 2010. Arquivologia 2.0: a informação digital bumana. Florianópolis: Bookess.

Luz, Charlley. 2015. Primitivos digitais: uma abordagem arquivística. Salvador: 9Bravos.

Moreno, Nádina Aparecida. 2008. "Gestão documental ou gestão de documentos: trajetória histórica”, em Gestão em arquivologia: abordagens múltiplas, organizado por Linete Bartalo e Nádina Aparecida Moreno, 71-88. Londrina: Eduel.

Múnera Torres, María Teresa e Arilog Regina Pabón Ángel. 2002. "La gestión del conocimiento y su relación con la documentación”. Revista Interamericana de Bibliotecología 25 (2): 25-49.

http://www.brapci.inf.br/index.php/res/download/97743

Paes, Marilena Leite. 2004. Arquivo: teoria e prática. 3a. ed. Rio de Janeiro: Editora FGV.

Ponjuán Dante, Gloria. 2015. "La gestión del conocimiento desde las ciencias de la información: responsabilidades y oportunidades". Revista Cubana de Información en Ciencias de la Salud 26 (3): 206-216.

http://scielo.sld.cu/pdf/ics/v26n3/rci02315.pdf

Rondinelli, Rosely Curi. 2005. Gerenciamento arquivístico de documentos eletrônicos: uma abordagem teórica da diplomática arquivística contemporânea. 4a. ed. Rio de Janeiro: Editora FGV. 
Rosini, Alessandro Marco e Angelo Palmisano. 2003. Administração de Sistemas de Informação e a Gestão do Conbecimento. São Paulo: Pioneira Thomson Learning.

Rousseau, Jean-Yves e Carol Couture. 1998. Os fundamentos da disciplina arquivística. Lisboa: Publicações Dom Quixote.

Santos, Vanderlei Batista dos. 2009. "A prática arquivística em tempos de gestão do conhecimento”, em Arquivísticas: temas contemporâneos, 3a. ed., organizado por Vanderlei Batista dos Santos, 175-223. Distrito Federal: Senac.

Schellenberg, Theodore Roosevelt. 2006. Arquivos modernos: princípios e técnicas. 6a. ed. Rio de Janeiro: Editora FGV.

Schuster, Carlos Eduardo e Cândido Ferreira da Silva Filho. 2005. "Sistemas de Informação para a Gestão do Conhecimento", em Tecnologia da informação para a gestão do conbecimento: teoria e estudos em organizações, organizado por Cândido Ferreira da Silva Filho e Lucas Frazão Silva, 37-56. Campinas: Editora Alínea.

Schuster, Carlos Eduardo, Cândido Ferreira da Silva Filho e José Francisco Calil. 2005. "Tecnologia da Informação para a Gestão do Conhecimento: Um estudo em uma empresa do setor de bebidas”, em Tecnologia da informação para a gestão do conbecimento: teoria e estudos em organizações, organizado por Cândido Ferreira da Silva Filho e Lucas Frazão Silva, 81-98. Campinas: Editora Alínea.

Silva Filho, Cândido Ferreira da e Lucas Frazão Silva. 2005. "Da Aprendizagem à Gestão do Conhecimento", em Tecnologia da informação para a gestão do conhecimento: teoria e estudos em organizações, organizado por Cândido Ferreira da Silva Filho e Lucas Frazão Silva, 23-36. Campinas: Editora Alínea.

Silva, Edna Lúcia da e Estera Muszkat Menezes. 2005. Metodologia da pesquisa e elaboração de dissertação. 4a. ed. Florianópolis: UFSC.

https://projetos.inf.ufsc.br/arquivos/Metodologia_de_pesquisa_e_elaboracao_ de_teses_e_dissertacoes_4ed.pdf

Silva, Margareth da. 2017. O arquivo e o lugar: custódia arquivística e a responsabilidade pela proteção aos arquivos. Niterói: Eduff.

Silva, Wellington Diolice Felix da. 2003. Introdução à gestão da informação. Campinas: Alínea.

Soares, Rosana Rombi e José Nicolas Albuja Salazar. 2005. "Tecnologia da Informação e Mudanças Organizacionais: um estudo em uma empresa de bens de capital", em Tecnologia da informação para a gestão do conhecimento: teoria e estudos em organizações, organizado por Cândido Ferreira da Silva Filho e Lucas Frazão Silva, 127-158. Campinas: Editora Alínea.

Sonaglio, Claudia Maria, Fladimir Fernandes dos Santos e Pascoal José Marion Filho. 2008. "A Empresa que Aprende: a nova gestão da economia globalizada", em Administração: teoria sistêmica e complexidade, organizado por Milton Luiz Wittmann, 117-137. Santa Maria: Editora UFSM.

Sousa, Renato Tarciso Barbosa de. 2009. "A classificação como função matricial do que-fazer arquivístico”, em Arquivística: temas contemporâneos, 3a. ed., organizado por Vanderlei Batista dos Santos, 79-172. Distrito Federal: Senac.

Sousa, Renato Tarciso Barbosa de. 2008. "Em busca de um instrumental teórico-metodológico para a construção de instrumentos de classificação de documentos de arquivo”, em Gestão em arquivologia: abordagens múltiplas, organizado por Linete Bartalo e Nádina Aparecida Moreno, 11-52. Londrina: Eduel. 
Tonini, Regina Santos Silva. 2006. Custo na gestão da informação. Salvador: EDUFBA, Petrobrás.

Volpato, Gilson Luiz, Rodrigo Egydio Barreto, Helene Mariko Ueno, Enilze de Souza Nogueira Volpato, Percília Cardoso Giaquinto e Eliane Gonçalves de Freitas. 2013. Dicionário crítico para redação científica. Botucatu: Best Writing.

Wittmann, Milton Luiz e Alisson Eduardo Maehler. 2008. "Administração: do pensamento grego à teoria da complexidade", em Administração: teoria sistêmica e complexidade, organizado por Milton Luiz Wittmann, 15-39. Santa Maria: Editora UFSM.

Para citar este texto:

Santos, Henrique Machado dos e Gabriela Luisa Krawszuk. 2020. "Gestão do conhecimento organizacional: tratamento arquivístico para reuso da informação administrativa”. Investigación Bibliotecológica: archivonomía, bibliotecología e información 34 (83): 103-127.

http://dx.doi.org/10.22201/iibi.24488321xe.2020.83.58146 